\title{
Appreciating the image of God in all humanity: Towards a pastoral response to skin lightening as image enhancement to exit dark skin
}

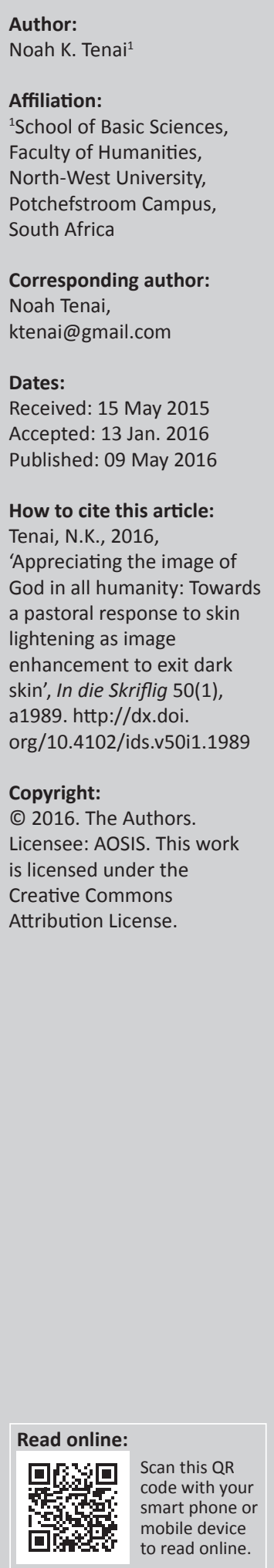

The practice of skin lightening is prevalent amongst dark-skinned people globally. Various current studies that map this practice and that seek motivations behind the practice are examined. It is observed that through shrewd marketing, dark-skinned people are offered a promise of a better quality of life, obtained by a lighter skin, through the use of skin lighteners. In spite of the severe health risks involved, the promise is ostensibly irresistible to some darkskinned persons. A pastoral response is offered that affirms the full personhood and complete humanity of dark-skinned people as fully human and whole in their dark skins.

\section{Introduction, background and premise}

This article hinges on the proposition that a Hollywood, or rather a media perception of image, strengthened by unrealistic advertising promises, creates a sense of dissatisfaction with the self. This is arguably worsened by possible existing after-effects of colonialism of the dark-skinned people by white people, which creates a sense of inferiority and a desire on the part of the darkskinned to be like the white coloniser. This dissatisfaction particularly pertains to dark skin, hence the desire to change one's dark skin to light skin. Theologically this mindset undermines people's unique image of God. Stated differently, the desire to alter the Craftsman's (God) perfect hand by exiting, weakening, and diluting one's skin colour, suggests doubt and dissatisfaction of the perfection of God. This undermines the aesthetics of each individual. In response therefore, it is imperative to cultivate a constructive and affirming view of oneself that is informed by a thorough understanding of the perfectum and aesthetics of created human beings. Such an approach fosters wholeness, positive image and contributes to appreciation of the Creator

The use of skin-lightening products for cosmetic purposes is a worldwide practice. Light skin is viewed as a standard of beauty globally, and particularly amongst dark-skinned populations. Blay (2011) observes that skin lightening as it manifests in contemporary times, is disproportionately practiced within communities of people of colour. Mahé (2014) notes that a sizeable percentage of dark-skinned populations frequently uses skin-lightening compounds.

A recent World Health Organization (WHO 2014) report demonstrates that women from Africa, the Middle East, Asia and Latin America frequently use skin-lightening or bleaching products. The report also indicates that the practice exists prominently amongst dark-skinned populations in Europe and North America. The report further shows that 25\% - 95\% of women in Sub-Saharan Africa use skin-lightening products. In Mexico, the skin-lightening products are widely available in pharmacies, beauty aid stores, and health stores (2014:40).

An earlier WHO (2011) publication, Preventing disease through healthy environments: Mercury in skin lighting products indicates that in Mali, Nigeria, Senegal, South Africa and Togo 25\%, 77\%, 27\%, $35 \%$ and $59 \%$ of women, respectively, use skin-lightening products on a regular basis. The publication further notes that in 2004 nearly $40 \%$ of women surveyed in China, Taiwan and Hong Kong, including Malaysia, the Philippines and the Republic of Korea, reported using skin lighteners. It is also reported that in India $61 \%$ of the dermatological market consists of skin-lightening products.

A cross-sectional study in Italy by Cristaudo et al. (2013) recognises, for example that skinlightening products have become increasingly common in European cities. Skin-lightening products that are commonly used are accessible as creams, milks, oils, ointments and soaps which are easily purchased at local street markets. The products are mainly used amongst immigrants, 
especially women. The study reveals that a majority of those who use skin-lightening products in Europe originated from Africa, Latin America, Asia and other unknown areas. The study observes that $40.2 \%$ of immigrant women use skinlightening products. The women who use skin-lightening products tend to be younger, with a higher level of education.

The use of skin-lightening products in the Arab world has not been fully documented. However, results of a survey done by AlGhamdi (2010) at an outpatient clinic of a university hospital in Saudi Arabia, reveals that the use of bleaching agents is very common amongst Saudi women. The survey indicates that numerous women of different ages, class and marital status, seek a lighter skin complexion and consequently use bleaching products. The findings of the Saudi Arabian survey coincide with another study by Hamed et al. (2010) that investigates the determinants, prevalence and user's awareness associated with the use or misuse of skin-lightening products amongst women living in Jordan. The results of this study indicate that skin lightening is common amongst $60.7 \%$ of the respondents.

A West African cross-sectional survey (Atadokpédé et al. 2015) aimed to evaluate the prevalence of skin-bleaching in public and private colleges of general education (CEG) in Bohicon, a city in central Benin, shows that the prevalence of voluntary depigmentation (VD) or skin-bleaching is $36.6 \%$. The results of the survey further advances that VD is a mainly female practice in Africa, with a prevalence ranging from $25 \%$ to $67 \%$ in West Africa. The findings of an existing study by Akortha et al. (2012) in Nigeria indicate that the use of skin-lightening or bleaching creams is increasing not only among women but also amongst men. The study further indicates that skin-bleaching is widespread amongst commercial sex workers who disguise their occupation in the clinic data as fashion designer because of the stigma linked to prostitution. Another study by Yousif et al. (2014) that examines the use of bleaching creams at a secondary school in central Sudan reveals that $51 \%$ of both boys and girls use skin lighteners with the face being the main application site. In South Africa, a recent study by Dlova et al. (2014) establishes that skin lightening is prevalent in a third (or over 4 million) of the population of both African and Indian women.

Blay (2011:5) observes that skin-bleaching is nothing less than a way of life in Africa, as demonstrated by the fact that in Lagos (Nigeria) 75\% of traders, in Dakar (Senegal) 52\%, and in Pretoria (South Africa) 35\% of the population use skinbleaching products. In Bamako (Mali) $50 \%$ of the female population uses skin-bleaching products. In Ghana, 30\% of the population, mainly women, and $60 \%$ of Zambian women aged 30-39 use bleaching creams. Eight out of every ten women in Cote d'Ivoire use skin-lightening products on a regular basis.

The foregone discussion demonstrates a widespread use of skin lighteners, a practice that is mainly evident amongst the dark-skinned people, particularly in Africa and amongst
Africans in the diaspora. The use of skin-lightening products is also a common occurrence in Asia and in Latin America. Although women are the main practitioners, men too use skin-lightening products. Nevertheless, despite the dangers and risks associated with the application of skin-lightening products, widespread use remains.

Akortha et al. (2012:7), Atadokpédé et al. (2015:3), WHO (2014:40), and Yousif et al. (2014:534) point out the dangers associated with skin-lightening products. In summary they indicate that skin-lightening products are dangerous because they contain chemicals such as hydroquinone, corticosteroid, or mercury, which leads to Cushing's syndrome, vulval warts, pitch-black pigmentation, fragile skin, colloid milium ochronosis and scabies, amongst other illnesses. The use of skin-lightening products also exacerbates illnesses such as adrenal insufficiency, diabetes, hypertension, renal damage, insomnia, memory loss, glaucoma and cataracts. Charles (2010:33-35) also notes that lactating mothers who bleach their skin also pass on mercury to their babies. Thus, whilst the skin lighteners offer a promise for a lighter skin tone including a promise to access a better quality of life, the outcome in some cases is to the contrary. The practice creates an environment contingent to increased health complications.

In view of the prevalent use of skin-lightening products and their dangers and risks, what are the factors that sustain the use and application of such products? What are the motivations behind the skin-lightening phenomenon? How may these motivations be theologically understood within a context of one's conception of the self as a sufficient and beautiful creation of God? What approaches could be employed to productively interrogate the practice of skin lightening to constructively guide people to live in a manner that affirms the sufficiency and aesthetics of the individual as God's artwork (aesthetics of God's image in oneself)?

\section{Motivations for sustained use and application of skin-lightening products}

To understand the factors underlying skin-lightening consumption, this section discusses some factors that sustain the use and application of such products as well as motivations behind the skin-lightening phenomenon. Two main factors, centred on the psyche, can be highlighted. Firstly, media (i.e. television, movies, advertisements) use images of perfect persons as light and smooth-skinned, and this exerts pressure on the image of sensitive people. Advertisers and marketers exploit this gap and market for their skin-lightening products. Secondly, the desire for dark-skinned people to lighten their skin is motivated to perceivably access privileges and benefits.

The media, as Bhattacharya (2012:2-5) and Glenn (2008:15-18) observe, does not only respond to a pre-existing need, but actually create a need by depicting having a dark skin as 
a painful and depressing experience. Black women, for example rarely play romantic leads in Hollywood movies, but those who do are of a lighter skin tone. The media project dark-skinned people as unhappy, suffering from low self-esteem, and by using skin lighteners they undergo a transformation of not only their skin colour but also their personality and fate. Advertising contributes to perceptions that a light skin is more desirable than a dark skin mainly through portrayal of light-skinned models as symbols of what is attractive and desirable. Women studied in Jordan admitted that advertisements influenced them to prefer lighter skin tones. According to Dlova et al. (2014:239-240) women acknowledged that their preference for a light skin was reinforced by the way beauty products were advertised. It is apparent that television advertisements have generally and largely contributed to the practice of using skinlightening products. The majority of television commercials, as Hamed et al. (2010:417) posit present light-skinned models as more attractive; they are also more likely to achieve success in terms of accessing employment opportunities, including access to better options on mate selection. Such adverts influence television viewers to prefer light skin tones.

Advertisers communicate the message that a light skin signifies beauty. As such, skin-lightening products present a means to attain that beauty (Meyers 2008:25-27). With the proliferation of 'the Internet of things' within the present-day Africa, skin-lightening products are strategically advertised everywhere, including on local radio and television stations as well as on huge billboards throughout urban areas and major roads (Hunter 2011:146-148). The adverts generally depict a close to naked (light-skinned) female, positioned close to a series of products with captions that generally indicate that 'nice' skin is obtained through the use of these products. The adverts contribute to a singular impression that a light skin is divinely superior and fundamental to civilisation, cleanliness, modernity, luxury, beauty, femininity, and desirability. Adverts reinforce a notion of light-skinnedness as a symbol of respectability and social power that darkskinned people could obtain through the use of skinlightening products. The message is that dark-skinned people can change their circumstances of supposed inferiority and gain access to respect and power through consumption of skin-lightening products. The manufacturers' success in marketing and selling skin-lightening products to darkskinned people is predicated upon a colonial promotion of idealised whiteness.

The perceived inferiority of blackness that has its origins in colonialism by white people has resulted in the desire amongst the dark-skinned people to be the white master. Hall (1995a; 1995b; 1999) observes that skin-bleaching occurred because the cultural domination of blacks by whites caused some blacks to internalise the white skin as more valued and ideal. Chisholm (2002) suggests that some blacks bleached their skins because they wanted to become white. Mire (2001:25-28) in an analysis of Internet skin-bleaching advertisements, finds that the politics of colourism which gave social benefits and access to light-skinned over dark-skinned people, drives skin-bleaching. Blay (2011:6) adds that the historical institutions of colonialism and enslavement, including ongoing worldwide white supremacy, are the leading and responsible reasons for skin lightening.

The challenge, however, is to understand particular ways in which colonialism and the ongoing white supremacy to influence perceptions, feelings and thoughts regarding skin colour, and the subsequent contribution to the decision to lighten one's skin. There seems to be a very clear link between skin lightening and historical colonialism with attended superiority of whiteness. The preferred treatment of people based solely on their skin colour, including a system of hierarchical perception of value and a discriminatory treatment based on skin colour seems to be a seedbed for the use of skin-lightening products. As a global power structure, white supremacy, as Blay (2011:6-7) argues, preserves and protects a system of wealth, power, and privilege. Whiteness comes with privileges and benefits. There is exclusive value assigned to whiteness that involves, according to Blay (2011:7), 'a series of immunities, privileges, rights, and assumption'.

From the position of privileges and benefits, it is socially and psychologically understandable why one would pursue skin lightening as a way to upgrade one's social standing. Being white unlocks opportunities for a better quality of life at least ushered by privileges. Importantly, this psychological projection happens unconsciously, which skin-lightening product users may deny. Blay (2011:7-8) insightfully notes that most individuals who bleach their skin vehemently reject accusations that they desire to be white because they are aware that no amount of chemical intervention will actually render them white. Blay's (2011) comment is illuminating. It indicates that the centuries of 'whiteness inoculation' during colonialism are lived unconsciously. Accordingly, there is a clear but complex connection between the legacy of worldwide white hegemony and the presentday global skin-lightening phenomenon. For instance, as Blay (2011:20) notes, whiteness as the explicit ideal and the feminine aesthetic ideal in Europe, has had an impact on women of all races and cultures, and has led to the cosmetic efforts of skin lightening.

In Tanzania and Ghana, as observed by Blay (2009; 2011:23) and Lewis et al. (2011), women who had bleached their skins claimed that they did so in order to remove pimples, rashes and skin diseases; to have a soft skin; to be white, beautiful (and more European looking); to satisfy one's partner or attract mates of the opposite sex; to impress or satisfy peers; and to feel clean and fresh. Such reasons seem to point directly to an aspiration to get the approval of others and to be seen as beautiful, using frameworks and criteria for beauty that replicate Eurocentric beauty paradigms. The implication here is that a lighter skin tone obtained from skin-bleaching enables one to access particular social networks, facilitates the performance of particular social identities, enables 
the performance of modernity, attracts attention, ignites heterosexual (male) desire and boosts marriageability or husband maintenance. ${ }^{1}$

In a nutshell, skin lightening supposedly assists one to move upstream towards whiteness, which is coveted by many. Even a perception that light skin retains partners, in itself suggests that even men themselves desire and strive for whiteness as the ideal. Thus, the desire for whiteness can undoubtedly be admitted as a contributor and driver to applying skin-lightening products. But how have people responded to skin lightening?

\section{Responses to skin lightening}

Despite the wide use of skin-lightening products, the practice has attracted responses that range from public ridicule to product legislation. However, the particular responses include the following four major responses: education -the general public and the consumers in particular had to be duly informed of the risks associated with the practice in order to change perceptions; regulation - that bleaching agents must responsibly be managed through legislations and that relevant regulatory bodies be empowered to effect the demands of the law(s); withdrawal - that all illicit and toxic products on the market be removed forthwith; and responsibility - that those who use lightening agents to treat pigmentation disorders do so with caution.

In Europe and America (Blay 2011:22; Peiss 1998:27), early Christian moralists likened face painting to idolatry. Women were therefore urged to abstain from all sorts of artifice in order to pursue integrity, wholesomeness, sexual chastity and natural beauty. The initial popular perceptions in Europe and in the USA were that women who painted their faces were prostitutes who did so as a way to advertise their immoral business. Men who whitened their skins were equal recipients of scathing criticism, including accusations that they were giving in to an emptiness that was common amongst women. As such, both men and women who whitened their skins went to great lengths to hide their actions, in order to circumvent open mockery. By hiding their practice, it became equally challenging, if not impossible, to provide any medical assistance in situations where the products used had harmful effects on the skin.

1.In Benin the initial use of skin lighteners was driven by a desire for a lighter skin

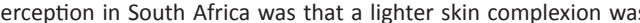
better than a dark skin. As such, the hue of one's skin was indicated as determining one's social hierarchy and consequent economic opportunity. In fact, more than third of those who participated in a survey, held a belief that a lighter skin tone increased their self-esteem, implied a higher socio-economic class, helped women to access better job opportunities, and increased women's chances of getting married or keeping a partner, as she would be considered beautiful by men. Indeed, the use of skin lighteners in South Africa represented a culturally linked perception of the social value of a light skin. The perception was pervasive, and as earlie alluded to, perpetuated by the use of light-skinned models to market skin lighteners and other cosmetics to black consumers (Dlova et al. 2014:236-240). The perceptions of respondents in a Jordanian study demonstrated that there was wide belief that a lighter skin tone represented beauty. The belief was a key wide belief that a lighter skin tone represented beauty. The belief was a key contributory factor to the use with self-esteem and youthfulness, including perceived increased chances of accessing better employment opportunities. Access to job and employment opportunities seemed to promote the practice. It was further indicated that the role of a lighter skin tone in mate selection, including the potential perception by men that a lighter skin tone was more attractive reinforced the use of skin lighteners (Hamed et al. 2010:415-419).
In a similar manner, as Blay (2011:23) and Tuma (2010) point out, the practice of skin lightening in Africa has generally attracted public disapproval. In particular instances, it was associated with commercial sex workers. Some media houses in Africa portray women who lighten their skins as uninformed, ill-advised and susceptible, whilst others even censure and mocked them. Additionally, others classify the skin-lightening practice as representing low self-esteem, selfhate and a colonial mentality. In other instances, skin lightening is seen as representing the moral character and the inner strength of those who engage in the practice. Skin lightening is also seen in other situations as representing an insult to the dignity of the black race in general and the African in particular, and those who bleach their skins are accused of betraying their cultures. On the other hand, African men who use skin-lightening products are seen as effeminate and often an assumption is made that they are homosexual.

A West African study, Epidemiological and clinical aspects of skin bleaching in secondary schools in Bohicon, Benin (Atadokpédé et al. 2015), acknowledges skin-bleaching as a health problem in West Africa, and indicates that skin-bleaching poses a problem in terms of the loss of 'core values' in favour of artificial ones. The study suggests an urgent youth outreach program to fight against the scourge, which it claims, is a key contributor to poor academic performance, particularly within Benin's secondary schools.

A South African study, Women's perceptions of the benefits and risks of skin-lightening creams in two South African communities (Dlova et al. 2014), acknowledges what it calls the 'cutaneous effects' that are associated with the use of skin-lightening products. The study claims that a poor understanding of the risks associated with the use, augments the skin-lightening practice. As such, the study advocates for public education campaigns to teach consumers about the risks of the products. It further calls for effective policing of informal markets in order to rid the markets of any illicit skin-care products.

A Sudanese study, The use of bleaching creams among Central Sudan students (Yousif et al. 2014), provides a rather detailed and equally helpful approach to skin-bleaching practice. The study acknowledges the abuse of skin-bleaching creams amongst central Sudanese students, and attributes the practice to lack of health awareness on the dangers of the practice and ignorance on the causative factors. The study calls for educational lectures that would discuss the hazards of the toxic agents in the skin-bleaching products, including putting restrictions on such agents as corticosteroids for prescription only. The study demands that laboratories be provided in order to check the active ingredients and concentration of active skin-bleaching ingredients in the legally imported products. The study recommends that all cosmetic products should declare the contents and concentration of all ingredients. The study calls for an epidemiological surveillance to withdraw all cosmetics that contain corticosteroids, mercury, hydroquinone or any other unlicensed skin-care product from the market. The study 
further calls the mass media and family members to positively assist in the counselling of young girls, and finally calls for competent authority awareness against the abuse of skin-bleaching agents.

A report of the WHO (2014:300-301) on Dermal exposure, acknowledges that even though regulation and labelling requirements in some countries had been effected, more information for the general public about the possible effects due to exposure of hazardous substances in consumer products has to be made available. The report indicates that metals such as lead and mercury in skin lighteners have to be identified and eliminated and that the consumers must be informed about their possible effects.

The findings of an investigation into Mutagenic and genotoxic screening of eight commonly used skin whitening creams in Nigeria (Akortha et al. 2012:9) are that bleaching creams are 'genotoxic' to the body cells. It recommends that the use of bleaching creams had to be avoided, except when prescribed by an expert physician. It advises government and consumer protection agencies to embark on aggressive anti-bleaching campaigns and awareness programmes with a view to educate the public on the adverse effects of skin-bleaching. The investigation recommends that the public has to be enlightened on the need to change the perception that a light skin is beauty. The public also has to be made aware that by the practice of good personal hygiene, good diet, and a healthy lifestyle, it is possible for the skin to look good and radiant.

An analysis entitled, Qualitative and quantitative estimation of hydroquinone in skin whitening cosmetics (Siddique, Parveen \& Zaheer 2012:227), recommends that there should be a regulatory body appointed by government to check the quality of cosmetics available.

A Jordanian study, Skin-lightening practice among women living in Jordan: Prevalence, determinants, and user's awareness (Hamed et al. 2010:419), recommends that any intervention against the use of skin lighteners has to consider the user's awareness of both the safety and the proper use of the product. The study calls for the development of realistic interventions, claiming that the safety and the potential hazards associated with the misuse of the products are a key to educating Arab women to start changing their beauty perceptions and to value their natural blemish-free, even-toned skins. The study advises that those who use skin lighteners for the treatment of pigmentation disorders have to be made aware of the proper use, including the factors that could hinder the efficacy of the products, and how to avoid the use of misbranded and adulterated skin lighteners.

\section{A theological reflection on skin lightening}

Skin lightening appears to be a need for dark-skinned people. It is a perceived need to improve their physical appearance based on a preoccupation with body (im)perfection.
Arguably, skin lightening is an identity crisis motivated by socio-economic perceptions of the limitations of a dark skin. Indications that skin lightening represents an identity crisis points to a depressing reality that the very identity of skin-lightening consumers and their overall perception is based on a weak view of the self. Skin lightening feeds on low self-esteem and poor self-concept. One's self-image and esteem is central to one's social identity and humanhood because self-image contributes to how one regards oneself. The overt or covert psychological assumption is that when skin lightening is applied, it allows one to access superior benefits or high status, for instance retaining a husband, to be loved by many people, be viewed as more beautiful, et cetera. Further, skin lightening approximate and reflect progress towards lightness and the alleged socio-economic worth and privileges attached to it.

Apart from medical grounds, skin lightening may not necessarily be wrong but it is the underlying reasons that are questionable. The explicit or implied motives undermine or question the very essence of God as Creator (Ps 139:14; Gn 1:31). ${ }^{3}$ The question that therefore arises is what perspectives are found in the Christian Scriptures regarding skin, skin tone and skin lightening. Narrowly it seems there is no apparent value attached to skin colour in the Bible. However, Koslofsky (2014:795) comments that theologically all human bodies share a single origin in creation and a single descent from Adam, Eve, and Noah. The human body and its skin are fundamentally the same everywhere, but also deeply mutable and subject to divine intervention, from disfiguring curses to healing miracles. Stated simply, Koslofsky (2014:795) advances a theological and doctrinal argument. It is about God the Creator and the wisdom with which he created each individual as unique. Each person, whether light-skinned or dark-skinned, reflects the perfectum and aesthetics of God in human creation. Every human being was created in God's image (Gn 1:26-27). ${ }^{4}$ The human reflects God's perfect and complete art (perfectum) and reflects God's beauty (aesthetics) (Gn 1 31; Ps 139:14) to which human response should be doxology.

Ronning (2008) and Simango (2007:2013) discuss the meaning of human beings as bearing the image of God at length in their articles. They maintain that the image of God in the Old Testament (OT) is both moral and relational in perspective. It involves moral likeness to God and a relationship between God and man like that between parent and child. Linking the OT to the New-Testament meaning of the image of God, these scholars view unity in Christ as bearing the image of Christ. They illustrate that when one imitates Christ, one imitates both his moral excellence, and his submission to the

2.'1 praise you because I am fearfully and wonderfully made; your works are wonderful, I know that full well' (NIV).

3. 'And God saw everything that he had made, and, behold, it was very good. And the evening and the morning were the sixth day' (NIV).

4. Genesis 1:26-27 (NIV) states: Then God said, 'Let us make mankind in our image, in our likeness, so that they may rule over the fish in the sea and the birds in the sky, over the livestock and all the wild animals, and over all the creatures that move along the ground.' So God created mankind in his own image, in the image of God he created them; male and female he created them'. 
Father. When Paul says 'be imitators of God, as beloved children' (Eph 5:1), he has expressed the O-T idea of the image of God; imitate God not as a rival, along the lines suggested by the tempter, but as children in submission to him, following his commands which exhibit God-likeness.

The consummation of human beings as God's image-bearers is clearly outlined in the New Testament. Kelsey (2010:1008ff.) notes that there are four key New-Testament passages, namely Colossians 1:15; 1 Corinthians 15:49; 2 Corinthians 4:4, and Hebrews 1:3 which clearly indicate that Christ is the true image of God through whom human beings are united. This is the case for Christians whose destiny is in the reception of Christ's image as they are raised to new life. As such, Jesus alone is truly the image of God and others become likewise by 'imaging the image'. Thus human beings find their full humanity and completeness through Christ.

Ronning (2008) and Simango (n.d.) explain that Christ is the true image of God. He is the image of the invisible God. He is made in the likeness of man to effect the restoration of a sinner to the likeness of God. Jesus is the Son of God. Morally, he is like the Father (even though he is God). Through Christ's death on the cross, believers are individually adopted in God's family; they become his children (or sons) and they are to be morally like him. Through sanctification, the believer is being renewed into the image of God. Believers are called to be like Christ. In Christ, the two ideas of moral God-likeness and the relational aspect of sonship are brought together in Christ-likeness.

Whilst Ronning (2008) and Simango (n.d) insightfully explain the image of God morally and relationally, the reality of these emotional and psychological truths have significant implications for humanity. Being a child and daughter of God, as God's image bearer is transforming. It should transform people's personal views whether of shape, looks, skin, nationality, and any other factors that may be divisive. From this perspective, darkness of one's skin should be embraced with gratitude and happiness as true image of God. Any mentality or view outside this one constitutes theological poverty on creation and the doctrine of God himself. Arguably, skin lightening, as a desire to exit blackness constitutes poverty. It is empty poverty that accrues from not knowing one's position and personhood in God, through Christ. Such inner poverty tends to trigger more inner and material poverty, which has the real potential for more poverty. Skin lightening robs the dark-skinned people of their God-given identity as dark-skinned. It makes them feel psychologically inferior and desire to exit black skin and metamorphose to white skin. A question therefore may arise as to what could be done, and how could dark-skinned people's self-image be enhanced so as not to fall victim to the falsehood of merchandised lightness, and the unfortunate and false promise to exit blackness by means of a lighter skin?

How can churches offer a pastoral guidance to the challenge of skin lightening?

\section{Towards a guiding framework to people trapped in skin lightening}

In the light of the following seven aspects, it is imperative to construct a pastoral response that would guide people in their interface with the challenge posed by the practice of skin lightening: a realisation of how pervasive the practice of skin lightening was; knowing the marketing gimmicks employed by the manufacturers and marketers to sell the skin lighteners; awareness of the dangers that the practice posed to the health of the users of skin-lightening products, and by extension the entire human race; sensitivity to the motivations that drove the use of skin-lightening products; cognisance of the people's attitudes toward skin lightening, and the limitations of the structural measures that have been put in place by various national and regional institutions to curb the practice; consciousness of how some expressions of Christianity and some churches may have contributed to impoverishing the self-understanding and self-image of the dark-skinned peoples, and thus contributing to the desire to exit blackness, therefore further abetting the consumption of skin lighteners; armed and prepared by the knowledge that the Christian Scriptures, logic and experience are allies in the efforts aimed at affirming the full humanity and expression of dark-skinned people.

An appropriate pastoral response to the challenge posed by skin lightening has to be one that challenges the minds of the potential and current consumers in a way that affirms their self-understanding. It is equally necessary to ensure that there is a support system that provides guidance to those who run the risk of falling into the trap inherent in skin lightening. In addition, Christians should be capacitated to enable them to engage with the challenge of skin lightening and its risks within the public spaces where they live.

Firstly, in order to appeal to the mind, attention is directed to biblical texts that affirm a dark-skinned person's self and fullness in Christ, including those that indicate the goodness and completeness of God's handiwork. Biblical texts such as Genesis 1:31, Psalm 104:24;, and also Psalm 9:1-2 ${ }^{6}$ are useful in affirming the goodness and completeness of God's creation. God created the earth lovingly and called it good. The creation exists in a delicate balance, suitable for the nurturing of all life. Every single human being, as Smedt and Cruz (2014:135-156) and Thomas (2012:133-153) assert, no matter how much the image of God is marred by sin, or illness, or weakness, or age, or any other disability, still bears the status of being in God's image. This means that all people should be viewed with dignity and respect that is due to God's image-bearers. ${ }^{7}$ This has profound implications for how we view others and ourselves. It means that people of

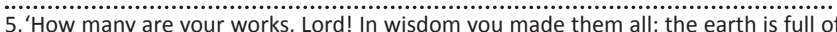
your creatures' (NIV).

6. Psalm 9:1-2 states: I will give thanks to you, Lord, with all my heart; I will tell of al your wonderful deeds. I will be glad and rejoice in you; I will sing the praises of your name, O Most High (NIV).

7. A detailed discussion on the link between the image of God in the OT and NT is extensively done by Ronning (2008) and Simango (2007; 2013; n.d.), which is at a slight tangent to the focus of this article. 
every race have equal dignity and rights. It goes further to mean that elderly people, those seriously ill, the mentally retarded and unborn children, deserve full protection and honour as human beings. This understanding of human beings should form the bedrock of guiding people to selfacceptance, positive self-concept, self-confidence and above all, realise that value and humanness is not derived from outward appearances such as skin colour but from our being in God, as his creatures created in his very own image. This reality is described in the Bible as follows:

... since you have taken off your old self with its practices and
have put on the new self, which is being renewed in knowledge
in the image of its Creator. Here there is no Gentile or Jew,
circumcised or uncircumcised, barbarian, Scythian, slave or free,
but Christ is all, and is in all. (Col 3:9-11; NIV)

Thus people should be pastorally guided to take this life's stance in order to fully appreciate themselves, which means, in cases where skin lightening is still applied, the motive will be appropriate. Thus a mindset shift is encouraged as a first step towards a model for responding to people who practice skin lightening.

Secondly, many people who apply skin-lightening products have developed dependence on them over time. As a prevalent phenomenon, there are psychological and emotional attachments connected to the use of these products. Therefore any efforts to discourage people are likely to be resisted due to, amongst other things, being viewed by peers as regressive. This suggests that further to biblical instruction, there should be supportive structures to reinforce one's decision. Thus, a pastoral support for individuals is encouraged. Pastoral support is about individuals assisting each other to emerge from skin-lightening traps, through enrichment groups for those at risk, such as ladies and girls. Effective support structures should be erected within the context of faith communities to strengthen and support those who resolve to stop using skin lighteners and maintain their natural complexion or skin colour. In this instance, there is need to reinforce this regained self-concept as rooted in realisation of God's perfect image and creation perfectum. Therefore supportive systems should be developed within the faith communities. Magezi $(2006 ; 2007)$ rightly notes

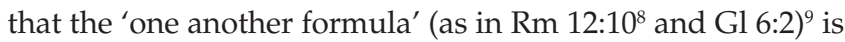
an important biblical approach in developing supportive ministries. Jacobs and Reupert (2014:2) in their comprehensive review of supportive counselling emphatically concluded that it is effective. The Huntley Centre (2006) explains that supportive counselling systems are used to facilitate optimal adjustment in stressful situations, amongst other things. Its practical components include empathy, sympathetic listening, intense confidence building, ventilation and expression of emotional material, encouragement, explanation and education, reassurance, guidance, practical help and behaviour modification.

8. 'Be devoted to one another in love. Honor one another above yourselves' (NIV).

9. 'Carry each other's burdens, and in this way you will fulfill the law of Christ' (NIV).
It is therefore advised that people who are instructed on the proper understanding of image and have adopted a constructive view of skin lightening and are considering moderating application of skin lighteners, be supported to gain confidence, and be affirmed on their new path. Clinebell (1984) named this approach Group pastoral counseling. This approach is invaluable for the life of the church regarding strengthening support towards taking a stand on life's issues (Brown \& Brown 2015:40-45; Mödinger 2012:118-120), in this case, skin lightening. These church groups will strengthen the application of biblical instruction, build confidence on the new path, and enhance empowerment of life skills to live life meaningfully, and with full appreciation of the self.

Thirdly, it is about engaging various publics or role players. Church people are also members of society who exist within the space of public life. They interface with life's challenges that require reflection and application of a Christian mindset to live meaningful lives. Magezi (2012) asserts that a church is a subsystem of society and community. Accordingly, people require guidance on how to encounter and respond to life issues in the real life spaces where they exist. This reality of life challenges theology to equip and empower people to engage with the world meaningfully. Mashau (2014) in his insightful missiological article on mission in the public square within the context of the city observes that the future of mission and missiology is in the city where people find themselves in creative spaces. Theology and ministry therefore need to engage with the public. To that end it is imperative that people are equipped to engage with the prevalent consumerism of skin lightening and constructively help people to cope. Ganzevoort (2009) in his practical theology navigational article, like other Practical Theologians, advises that the object of practical theology encompasses ordained ministry, church, faith, religion, culture and society. Accordingly, people need to possess skills to interface within these spaces and with issues such as skin lightening.

\section{Conclusion}

The prevalence of skin lightening as a practice is acknowledged as endemic mainly amongst the dark-skinned people globally. Though largely practiced by females, males too are involved. The media plays a critical role in advancing the need for the use of skin lighteners by projecting lighter skins as representations of what beauty is. Some of those who lighten their skins do so as a means to access better options including a better quality of life associated with whiteness or closeness to it. The key bleaching agents in the skin lighteners are very toxic and are responsible for serious health problems. With the various efforts aimed at either controlling or completely banning those bleaching ingredients notwithstanding, the practice of skin lightening is still ongoing. This article suggests a three-pronged model that seeks to provide a pastoral response to the challenge posed by the practice of skin lightening. By using biblical texts that portray the true status of dark-skinned people as part of God's created human family, as good and complete, it is hoped that an appeal to a mindset change is effective. 
The need for constructive support is acknowledged. As such, Christians are called upon to provide support to those who desire to stop the practice, and those who are at risk of giving in to the allure of skin lightening. In addition, Christians are called upon to actively engage with the challenge posed by skin lightening within the public spaces where they live.

\section{Acknowledgements Competing interests}

The author declares that he has no financial or personal relationships which may have inappropriately influenced him in writing this article.

\section{References}

Akortha, E.E., Niemogha, M.T. \& Edobor, O., 2012, 'Mutagenic and genotoxic screening of eight commonly used skin whitening creams in Nigeria', Bayero Journal of Pure and Applied Sciences 5(1), 5-10, viewed 15 April 2015, from http://dx.doi. org/10.4314/bajopas.v5i1.2

AlGhamdi, K.M., 2010, 'The use of topical bleaching agents among women: A crosssectional study of knowledge, attitude and practices', Journal of the European Academy of Dermatology and Venereology (JEADV) 24(10), 1214-1219.

Atadokpédé, F., Adegbidi, H., Koudoukpo, C., Téclessou, J., Degboé, B., Ango-Padonou, F. \& Yedomon, H., 2015, 'Epidemiological and clinical aspects of skin bleaching in secondary schools in Bohicon, Benin', Journal of Cosmetics, Dermatological Sciences and Applications 5(1), 1-6, viewed 15 April 2015, from http://dx.doi. org/10.4236/jcdsa.2015.51001

Bhattacharya, S., 2012, 'The desire for whiteness: Can law and economics explain it?', Columbia Journal of Race and Law, viewed 11 May 2015, from http://papers.ssrn. $\mathrm{com} /$ sol3/papers.cfm?abstract_id=1743267

Blay, Y.A., 2009, 'Struck by lightening: The transdiasporan phenomenon of skin bleaching', Jenda: A Journal of Culture and African Women Studies 14(1), 1-10.

Blay, Y.A., 2011, 'Skin bleaching and global white supremacy: By way of introduction', The Journal of Pan African Studies 4(4), 4-46.

Brown, P. \& Brown, M., 2015, 'Pastoral group counselling at a high security prison in Israel: Integreting Pierre Janet's psychological analysis with Fritz Perls' Gestalt therapy', The Journal of Patoral Care \& Counseling (JPCC) 69(1), 40-45.

Charles, C.A.D., 2010, 'Skin bleaching in Jamaica: Self-esteem, racial self-esteem, and black identity transactions', Caribbean Journal of Psychology 3(1), 25-39.

Chisholm, N.J., 2002, 'Skin bleaching and the rejection of blackness: Fade to white', Village Voice, viewed 1 May 2015, from http://www.villagevoice.com/ issues/0204/chisolm.php

Clinebell, H., 1984, Basic types of pastoral care and counseling, Abingdon, Nashville.

Cristaudo, A., D'llio, S., Gallinella, B., Mosca, A., Majorani, C., Violante, N., Senofonte, O., Morrone, A., Petrucci, F., 2013, 'Use of potentially harmful skin-lightening products among immigrant women in Rome, Italy: A pilot study', Dermatology 226 , 200-206, viewed 16 April 2015, from http://www.karger.com/Article/Pdf/348706

Dlova, N., Hamed, S.H., Tsoka-Gwegweni, J., Grobler, A. \& Hift, R., 2014, 'Women's perceptions of the benefits and risks of skin-lightening creams in two South African communities', Journal of Cosmetic Dermatology 13(3), 236-241.

Ganzevoort, R.R., 2009, 'Forks in the road when tracing the sacred: Practical theology as hermeneutics of lived religion', Presidential Address International Academy of Practical Theology, Chicago, 3 Aug 2009, viewed 11 May 2015, from www.iapt. org/wpcontent/uploads/2011/.../presidentialaddress2009.pdf

Glenn, E.N., 2008, 'Yearning for lightness: Transnational circuits in the marketing and consumption of skin lighteners', Gender and Society 20(10), 1-22.

Hall, R.E., 1995a, 'The bleaching syndrome: African American's response to cultural domination vis-à-vis skin colour', Journal of Black Studies 26(2), 172-184.

Hall, R.E., 1995b, 'The colour complex: The bleaching syndrome', Race, Gender \& Class 2(2), 99-110.

Hall, R.E., 1999, 'The bleaching syndrome: As per racism in the new millennium', IFE Psychologia: An International Journal 7(2), 1-20.

Hamed, S.H., Tayyem, R., Nimer, N. \& Alkhatib, H., 2010, 'Skin-lightening practice among women living in Jordan: Prevalence, determinants, and user's awareness', International Journal of Dermatology 49(4), 414-420.
Hunter, M.L., 2011, 'Buying racial capital: Skin-bleaching and cosmetic surgery in a globalized world', The Journal of Pan African Studies 4(4), 142-164.

Huntley Centre, 2006, 'Supportive counselling', viewed 11 May 2015, from http:// www.huntlycentre.com.au/updates/posts/view/17

Jacobs, N. \& Reupert, A., 2014, 'The effectiveness of supportive counselling, based on Rogerian principles: A systematic review of recent international and Australian research', Psychotheraphy and Counselling Journal of Australia 3(1), 1-12.

Kelsey, D.H., 2010, Eccentric existence: A theological anthropology, 2 vols., Westminster John Knox, Louisville.

Koslofsky, C., 2014, 'Knowing skin in early Modern Europe c. 1450-1750', History Compass 12(10), 794-806.

Lewis, K.M., Robkin, N., Gaska, K. \& Njoki, L.C., 2011, 'Investigating motivations for women's skin bleaching in Tanzania', Psychology of Women Quarterly 35, 29-37, viewed 27 April 2015, from http://pwq.sagepub.com/content/35/1/29.full.pdf+html

Magezi, V., 2006, 'Community healing and the role of pastoral care of the ill and suffering in Africa', In die Skriflig 40(3), 505-521.

Magezi, V., 2007, HIV and AIDS, poverty and pastoral care \& counselling: A home based and congregational systems ministerial approach in Africa, Sun Media, Stellenbosch.

Magezi, V., 2012, 'From periphery to the centre: Towards repositioning churches for meaningful contribution to public health care', HTS Teologiese Studies/Theological Studies 68(2), Art. \#1312, viewed 11 May 2015, from http://dx.doi.org/10.4102/ hts.v68i2.1312

Mahé, A., 2014, 'The practice of skin-bleaching for a cosmetic purpose in immigrant communities', Journal of Travel Medicine 21(4), 282-287.

Mashau, T.D., 2014, 'Reimagining mission in the public square: Engaging hills and valleys in the African city of Tshwane', viewed 11 May 2015, from http://dx.doi. valleys in the African city of Tshwane', viewed 11 May 2015, from http://dx.doi.
org/10.4102/hts.v70i3.2774 and http://www.scielo.org.za/scielo.php?pid=S025994222014000300014\&script=sci_arttext

Meyers, Y.J., 2008, Effects of African American skin tone on advertising communication, viewed 3 December 2015, from https://www.lib.utexas.edu/etd/d/2008/ meyersy02114/meyersy02114.pdf

Mire, A., 2001, 'Skin bleaching: Poison, beauty, power and the politics of the colourline', Resources for Feminist Research 28(3-4), 13-38.

Mödinger, J., The implementation of pastoral group counselling: A way to care for HIV positive young women living in South African township, viewed 4 December 2015 from http://citeseerx.ist.psu.edu/viewdoc/download?doi=10.1.1.455.3146\&rep= rep1\&type $=$ pdf

Peiss, K., 1998, Hope in a jar: The making of America's beauty culture, Metropolitan Books, New York.

Ronning, J., 2008, 'The image and likeness of God: Genesis 2-4 as sequel', ETS annual convention, Providence, RI, 19 November 2008, viewed 14 December 2015, from http://postbiblical.info/PDFS/image_of_God.pdf

Siddique, S., Parveen, Z. \& Zaheer, M., 2012, 'Qualitative and quantitative estimation of hydroquinone in skin whitening cosmetics', Journal of Cosmetics, Dermatological of hydroquinone in skin whitening cosmetics', Journal of Cosmetics, Dermatological
Sciences and Applications 2, 224-228, viewed 28 April 2015, from http://dx.doi. Sciences and Applications 2, 22
$\mathrm{org} / 10.4236 /$ jcdsa.2012.23042

Simango, D., 2007, 'The image of God (Gen. 1:26-27) in the Pentateuch: A biblicaltheological approach', M.A. dissertation, School of Old Testament, North-West University, Potchefstroom Campus, Potchefstroom.

Simango, D., 2013, 'The law and the image of God', Old Testament Essays 26(2), 445-470, viewed 14 December 2015, from http://www.scielo.org.za/scielo.php?script=sci_ arttext\&pid=S1010-99192013000200014\&lng=en\&nrm=iso

Simango, D., n.d., The image of God (Gen 1:26-27) in the New Testament, viewed 14 December 2015, from http://www.academia.edu/8116230/the_image_of_god_ gen_1_26-27_in_the_new_testament

Smedt, J. \& Cruz, H., 2014, The imago Dei as a work in progress: A perspective from paleoanthropology', Zygon 49(1), 135-156.

Thomas, P., 2012, 'The relational-revelational image: A reflection on the image of God in the light of disability and on disability in the light of the image of God', Journa of Religion, Disability \& Health 16(2), 133-153.

Tuma, H., 2010, 'The tragedy of remaining a slave: The art of black on black hatred', Afrik News, viewed 17 April 2015, from http://www.afrik-news.com/article18339. $\mathrm{html}$

World Health Organization, 2011, Preventing disease through healthy environments: Mercury in skin lighting products, World Health Organization, Geneva, viewed 7 April 2015, from http://www.who.int/ipcs/assessment/public_health/mercury 7 April 2015

World Health Organization, 2014, Environmental health criteria for dermal exposure, World Health Organization, Geneva, viewed 16 April 2015, from http://www.who. int/ipcs/publications/ehc/ehc_242.pdf

Yousif, A.K., Ahmed, A.A.E., Elmustafa, M.O. \& Ahmed, E.H.S., 2014, 'The use of bleaching creams among Central Sudan students', Pharmacology \& Pharmacy 5 , 532-539, viewed 15 April 2015, from http://dx.doi.org/10.4236/pp.2014.55063 